Научная статья

УДК 811.161.2'27 + 811.161.1'27

DOI: $10.18101 / 2686-7095-2021-1-21-32$

\title{
КОНЦЕПТ «ЖЕНЩИНА» В РУССКОЙ ФРАЗЕОЛОГИИ В СОПОСТАВЛЕНИИ С КИТАЙСКОЙ
}

\author{
(С) Лай Янь-цзюнь \\ магистрант факультета славянских языков и литератур, \\ Государственный политический университет (Чжэнчжи) \\ Тайвань, 116, г. Тайбэй, ул. Чжинань, 64, 2 \\ lisalai0106@gmail.com
}

\begin{abstract}
Аннотация. Статья посвящена анализу концепта «женщина» в русской фразеологии в сопоставлении с тайваньским вариантом китайского диалекта - южноминьским диалектом. Выявлены физические, психологические и социальные особенности женщин, отраженные во фразеологических единицах (ФЕ). Пословицы, поговорки и фразеологизмы представляют собой важные элементы в лингвокультуре того или иного народа. Они создаются на основе образного представления о каком-либо предмете действительности и таким образом в них отражаются история, культура, мировоззрение данного общества. У иностранцев могут возникать сложности в понимании и усвоении данного пласта языка, так как их языковая картина мира может отличаться от носителей другого языка и культуры. Проведенное исследование позволяет выявить типичные, т. е. стереотипные, представления о женщине в традиционных культурах, русской и тайваньской.
\end{abstract}

Ключевые слова: фразеология; женщина в языковой картине мира; стереотипы; гуманитарные ценности.

\section{Для цитирования}

Лай Янь-изюнь. Концепт «женщина» в русской фразеологии в сопоставлении с китайской // Вестник Бурятского государственного университета. Филология. 2021. Вып. 1. C. 21-32.

Давно известно, что язык играет важную роль при обмене информацией, знаниями, мыслями и эмоциями, а также является одним из главных средств для изучения культурных ценностей, мировоззрения и философии жизни того или иного народа. Как отмечает С. Г. Тер-Минасова, «культурная и языковая картины мира тесно взаимосвязаны, находятся в состоянии непрерывного взаимодействия и восходят к реальной картине мира, а вернее, просто к реальному миру, окружающему человека» $[14$, с. 52]. В этом аспекте исследования стоит обратить внимание на фразеологию, которая, по словам В. М. Мокиенко, «становится памятью языка, храня давно изжившие из себя, но сыгравшие некогда важную роль, его элементы и свойства» $[6$, с. 7$]$.

В одной из классических книг 春秋繁露 («Обильная роса летописи Чуньцю»), в которой зафиксированы древнекитайские моральные ценности, отражается отношение общества к мужчинам и женщинам, жившим в тот исторический период, что также можно считать культурной реалией, на сегодняшний день уже не акту-

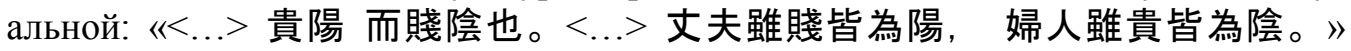
(« $<. .>$ Ценят ян и пренебрегают инь. <..> Мужчина, у которого статус ниже, 
все-таки представитель ян. Женщина, хоть у нее статус выше, все-таки представитель инь» (здесь и далее. - nер. наш); следует отметить, что в первой фразе не указано, кто конкретно и кого именно ценит). Данная идеология издавна существует в китайской культуре (и в обществе) как неписаный закон. Здесь мы не будем подробно объяснять философские понятия инь $и$ ян, остановимся лишь на том, что под инь понимается негативное начало, а под ян, наоборот, - позитивное начало. Данный принцип отражается и в народном творчестве, достаточно продуктивный пласт которого представляет собой фразеология, где концепт «женщина» занимает одно из ведущих мест.

В своем исследовании мы опираемся на понятие конщепт, который понимается нами как «оперативная содержательная единица памяти, ментального лексикона, концептуальной системы и языка мозга, всей картины мира, отраженной в человеческой психике» $[10$, с. $89-90]$. Таким образом, изучение концепта «женщина» во фразеологии русского, китайского языков и южноминьского диалекта позволяет нам раскрыть образ женщины, сформированный носителями данных языков и диалекта и отраженный в их культурной и языковой картине мира. Оговоримся также, что понятие «китайская культура» нами используется в самом широком понимании: рассматривается не только культура континентального Китая, но и культура всего китайскоязычного культурно-исторического континуума (кит. 中華文化).

По мнениию Г. А. Багаутдиновой, «в науке о языке использование антропоцентрического принципа ... занимает особое место» [5, с. 3]. Если условно трактовать знак инь и ян как общее понятие «человек», то данную бинарную оппозицию инь и ян можно интерпретировать как «женщина - мужчина». Подтверждает нашу презумпцию по поводу соотношения понятий «инь и ян» и «женщина мужчина» не только вышеуказанная цитата из древнекитайской литературной классики, но и работы многих лингвистов, в частности М. А. Алексеенко. Исследователь указывает, что «одним из основных параметров макросистемы 'лицо, человек' является половой признак, разделяющий ее номинанты на две подсистемы, объединенные значениями 'Мужчина' / 'Мужик', 'Женщина' / 'Баба'» [2, с. 61]. Вместе с тем уместно упомянуть, что языку, созданному на основе патриархальной идеологии общества, присущи гендерные предубеждения, и женщина как взрослый человек женского пола считается человеком второго класса [17, c. 5]. М. А. Алексеенко также отмечает, что «на всех ступенях иерархического членения макросистемы “человек” представлены феминизмы, т. е. лексические и фразеологические наименования, объединенные значением 'лицо женского пола' - Женщина, семантически противопоставленные маскулизмам - словам и фразеологизмам со значением 'лицо мужского пола' - Мужчина» [3, с. 416].

Рассмотрим образ женщины в русской и тайваньской культурах сквозь призму ее описания в русской фразеологии и ФЕ тайваньского варианта китайского (т. е. южноминьского) диалекта. В рассматриваемых ФЕ, как правило, представлен стереотипно закрепленный в сознании метафорический образ женщины, таким образом, фразеология, будучи антропоцентричной по своей сути, дает представление об образе человека посредством метафоры. Особое внимание обращается на образ женщины, стереотипно существующий в обществе, возникший на базе подобных ФЕ (resp. закрепившийся в них), а также на их психологические осо- 
Лай Янь-изюнь. Концепт «женщина» в русской фразеологии в сопоставлении с китайской

бенности и метафорический образ, созданный на основе физиологических характеристик женщин. Так, в частности, Д. В. Семенова анализирует концепты «мужчина» и «женщина» на материале ФЕ английского, русского и кабардинского языков и классифицирует ФЕ на типы, представляющие «“концептосоставляющий пласт социологических особенностей мужчин и женщин”, “концептосоставляющий пласт физиологических характеристик мужчин и женщин” и “концептосоставляющий пласт психологических характеристик мужчин и женщин”», что, в свою очередь, обеспечивает цель проведения глубокого гендерного анализа [11, c. 5].

Следует особо подчеркнуть, что феминизмы, т. е. лексические и фразеологические наименования, объединенные значением 'лицо женского пола', представлены на всех ступенях иерархического членения макросистемы «человек», в том числе и в лексикофразеологической системе языка, и в целом составляют достаточно четко организованную целостность $[3 ; 1]$.

Социальный образ женщин, отраженный в ФЕ. В русских и тайваньских пословицах и поговорках о женщине обнаруживаются различные слова, выражающие понятие лищо женского пола. Разные наименования женщины могут отличаться друг от друга своими особыми тонкими смысловыми оттенками. Как отмечает М. А. Алексеенко, «в качестве языковых экспонентов базового концепта 'женщина' выступает богатейшая ономасиологическая парадигма лексических, фразеологических и паремиологических наименований лиц женского пола (феминизмов) с первичными (прямыми) и производными (переносными) значениями» [2, с. 61]. Выявить определенные стилистико-прагматические характеристики определенной лексемы, номинирующей лицо женского пола, часто помогает конкретный контекст, однако в ФЕ, как правило, уже заложена та или иная оценка вне зависимости от контекста.

По наблюдениям исследователей, зачастую для ФЕ характерна отрицательная оценка женщин. При этом нельзя считать, что такая оценка всегда исключительно негативная. Яркий пример - две перифрастические номинации женщин: «слабый пол» (скорее, ближе к негативной оценке) и «прекрасный пол» (исключительно положительная оценка). А. Эмирова по этому поводу пишет следующее: «Обычно отмечается способность фразеологических единиц разного типа, преимущественно паремий, давать отрицательный аксиологический портрет женщины глазами мужчины» [16, с. 165]. В продолжение этой мысли сходную позицию обнаруживаем у М. А. Алексеенко: «Негативные стереотипы концепта 'женщина' в самых разнообразных подробностях, мелочах и деталях содержатся в многочисленных текстах культовой, художественной и публицистической литературы, фольклорных текстах и малых жанрах, наконец, во фразеологии, паремиологии и словарном составе различных языков» [2, с. 62].

Женщина как мать/мачеха. Следует сказать, что китайские моральные ценности и культура оказывают значительное влияние на повседневную жизнь тайваньского народа. В китайской культуре имидж мачехи имеет отрицательные коннотации, поэтому неудивительно, что в понимании тайваньского народа мачеха также является воплощением зла. Такой образ мачехи широко распространен в культуре многих стран мира, в частности в русской, и представляет собой контраст с образом доброй, ласковой родной матери. Считается, что у мачехи плохой 
характер, поэтому ее сравнивают с медведем: в лесу медведь, а в дому мачеха. А в тайваньской культуре мачеху сравнивают с весной, так как у мачехи неровный характер, а весенняя погода - неустойчивая и непредсказуемая: 春天後母面 (досл. «Весна - лицо мачехи»). В связи с тем, что мачеха обычно неприязненно относится к детям мужа от предыдущего брака, русские говорят: из дому гонит мачеха, а из лесу медведь, а тайваньцы: 前人子, 不 敢吃後母奶 (досл. «Ребенок от бывшей жены не смеет питаться (грудным) молоком мачехи»).

Мать - опора каждого человека. В русских пословицах и поговорках можно увидеть, что она приносит радость детям: «Птица радуется весне, а младенеи матери». Кроме того, мать способна греть душу ребенка, поэтому ее сравнивают с солнцем: «При солнылике тепло, при матери добро». Считается, что мать умеет заботиться о детях лучше отца. Как говорится: «Без отиа - полсироты, без матери - полный сирота». Подобная способность матери обнаруживается и в южноминьских $\Phi \mathrm{E}$ : 雞 母娶子會輕鬆, 雞公娶子會拖帆 (досл. «Курице легко завести детей, петуху неловко завести детей»). Очевидно, что здесь курица сопоставлена с матерью, а петух, соответственно, с отцом. Любовь матери к детям так велика, что мать готова делать всё для своих детей, в том числе жертвовать жизнью. В древности рождение ребенка было мучительным и опасным процессом, поэтому говорят, что 田螺吐団為団死 (досл. «Живородки погибают из-за рождения потомства»).

Анализируя русские и южноминьские пословицы и поговорки, посвященные матери и мачехе, можно заметить, что иногда встречается и (более) положительный образ мачехи, например: «Не всякая мачеха недруг», однако между матерью и мачехой все равно существует некое неустранимое различие. Данную точку зрения разделяют и носители русской, и носители тайваньской культуры: «Тепла, да не как лето; добра, да не как мать»; 銅鑼恰打銅羅聲, 後母恰好後母名 (досл. «Как ни бей в гонг, из него раздается звук гонга, как ни старается мачеха, останется она мачехой»).

Женщина как жена. Традиционно понятия брака и семьи играют существенную роль в китайской и русской культурах. Как говорится: 男大當婚, 女大當嫁 (досл. «Когда мужчина достигает определенного возраста, он должен жениться; как женшина достигает определенного возраста, она должна выйти замуж»). Подобное требование к жене в русской культуре отсылает к книге «Домострой». Процитируем здесь фрагмент, который отражает статус и образ женщины в браке: «Во всем она [жена] должна покоряться мужу; а что муж накажет, с любовью и страхом слушать и исполнять по его наказу и по сему писанию» [7].

Хотя у жены статус ниже мужа, она способна оказывать значительное влияние на семью. По этому поводу русские говорят: «Муж - голова, жена - шея: куда шея повернет, туда и голова повернется». Следовательно, хорошая, умная жена умеет помочь мужу делать семью лучше: 聽某嘴, 大 富貴 (досл. «Слушаться жену - появятся огромные богатства»). Если у жены характер плохой, то не только мужу, но и всей семье будет очень тяжело. Последствия заключения брака со злой женщиной можно увидеть в такой поговорке: 取得多某, 較慘三代無烘 爐、四代無茶鈷 (досл. «Худшее, что может произойти в результате заключения брака с плохой женой, - нет печи у трех поколений семьи, нет чайника у 
Лай Янь-изюнь. Концепт «женщина» в русской фразеологии в сопоставлении с китайской

четырех поколений семьи»). Последствия брака с плохой женщиной так ужасны, что «лучше в море утопиться, чем на злой жениться».

Важность жены для мужа подчеркнута и в следующей русской поговорке: «Без жены как без шапки», метафорическая база которой основана на одной из главных климатических особенностей России - холод. Поскольку в давние времена религиозная вера имела большое значение в духовном мире тайваньского народа, жена сопоставлялась с самым главным богом даосизма - Нефритовым императором: 一個某，卡好 三身天公祖 (досл. «Жена лучше трех Hефритовых императоров»).

Обобщая сказанное, можно сделать вывод, что мужчине стоит тщательно выбирать себе жену. В пословицах и поговорках русского языка и аналогичных единицах южноминьского диалекта обнаруживаются различные способы и правила, по которым рекомендуется выбирать себе подходящую женщину. С одной стороны, как говорится, «Жену выбирай не глазами, а ушами», т. е. надо придать серьезное значение тому, как и что она говорит, а с другой - стоит наблюдать, как ведет себя ее мама: 買田看田底, 娶某看娘禮 (досл. «При покупке поля надо наблюдать почву, при выборе себе жены надо смотреть на ее маму»).

Женщина как помеха и неполноценный человек. В традиционной китайской культуре (и обществе) существует неравноправие между мужчиной и женщиной: мужчину ценят, а женщиной нередко пренебрегают. Как говорится, «飼查 某子是了錢貨》 (досл. «Ребенок женского пола - убыточный товар»). Такие нравственные ценности культивировались на протяжении не менее чем одного тысячелетия назад, и можно сказать, что здесь следует учитывать историческое влияние аграрного общества на формирование данных ценностей такого рода.

Раньше считалось, что судьба ребенка женского пола такова: женщина выходит замуж и больше не принадлежит родной семье, она станет членом другой семьи, поэтому говорят, что 查某人, 賊 (досл. «Женщина - вор») и 查某子飼大, 別人的 (досл. «Кормили дочь до того, как она вырастет, (а) она станет чужой»). Данные поговорки показывают, что дочь в определенной степени является помехой и неприятностью для родной семьи, так как родная семья «потратила» денежные средства на нее, а она не приносит выгоды. Несмотря на то, что в русских пословицах зафиксирован и позитивный образ дочери, но отмечается, что она все-таки принадлежит другой семье (ср. «Дочь - матери помощнища. Дочь - чужое сокровище»).

В русских поговорках, пословицах и вообще в живой речи нередко встречается слово «баба», которое означает взрослую женщину и в словарях отмечено как разговорно-сниженное. Приведем следующий пример для демонстрации негативного образа женщины: «Баба с возу, кобыле легче». Отсюда можно заключить, что женщина рассматривается как лишний груз, который осложняет дело. Кроме того, она считается неполноценным человеком, который хуже человека мужского пола: «Курице не быть петухом, а бабе мужиком; Курица не птица, [а] баба не человек».

Физиологические характеристики женщин, отраженные в ФЕ. В физиологические характеристики человека входят его возраст, внешность и физические качества. Ниже мы проанализируем ФЕ в русском языке и южноминьском диа- 
лекте, в которых дается представление о физиологических характеристиках женщин.

Возраст. Уместно вспомнить, что замужество представляет собой очень важное и иногда даже необходимое событие для женщины в историческом прошлом (ср. «Хоть за старияа, лишь бы в девках не остаться»). В этом плане возраст понимается как одна из ключевых характеристик девушки, которая определяет ее возможность выйти замуж. Несмотря на то, что в давние времена не было точной возрастной границы брачного возраста, в русских ФЕ обнаружен возможный вариант: «<...> к 20 годам она уже считалась перестарком. За 21 год < ..> отошла от призыва. В 25 лет она уже теряла надежду выйти замуж и переходила в разряд cтарых дев» [8, с. 296].

Рассмотрим теперь ФЕ южноминьского диалекта, касающиеся брачного возраста женщин. Как говорится, 查某团仔, 十八變 (досл. 《Девушка изменяется 8 возрасте 18 лет»). Девушка, которой исполнилось 18 лет, «достигает подходящего возраста для замужества» $[18$, с. 33]. Считалось, что у девушки идеальный период для замужества заканчивается к 30 годам, так как 男人三十一枝花，女人三 十老人家 (досл. «Мужчина 30-летний - иветок, женщина 30-летняя - стару$x a »)$.

Красивая внешность как украшение женщины. Красивая внешность женщины описывается и в русских ФЕ, и в ФЕ южноминьского диалекта, к примеру: глаза у нее - все мужчины будут ее. Как замечает древнекитайский мыслитель Гао Цзы: «Любить прекрасные вещи - натура человека, не странно, что красивая женщина может привлечь внимание мужчин» (ср. «На красивый цветок летит и мотылек»), своей красотой делать ему приятно: 看某媠, 無酒嘛天天醉 (досл. «Смотришь на красивую жену - и каждый день пьянеешь без вина»). Данная шутливая пословица как нельзя наглядно демонстрирует силу женских чар - женская красота даже способна довести мужчину до состояния опьянения (ср. «жена красавииа - безочному (слепому) радости»).

Эталон красоты может варьироваться в разных странах и культурах, и люди, которые принадлежат даже к одной и той же культуре, могут по-разному ее воспринимать. Однако, исследуя русские и южноминьские ФЕ, можно заметить, что в прошлом белая кожа женщины в русской и тайваньской культурах оценивалась высоко: всего милее, у кого жена всех белее; 一白蔭九秀(水) (китайское выражение означает, что одно качество «белая кожа» может прикрыть 9 недостатков).

Следует подчеркнуть, что хотя красота является большим плюсом для женщины, но в значимости она уступает уму. Как говорится, «красота приглядится, а yм пригодится». В связи с этим можно сказать, что красивая внешность лишь украшает женщину и не является важным качеством женщины.

Физические качества как проявление внутренних качеств. По мнению ученых, одной из особенностей метафоризма в русских и китайских пословицах является то, что «физический признак предмета переносится на человека, способствуя выделению и обозначению психических свойств» [9, с. 79]. В поэме Н. А. Некрасова «Мороз, Красный нос» описывается идеальный образ русской женщины: «В игре ее конный не словит, В беде - не сробеет, - спасет: Коня на скаку остановит, В горящую избу войдет!». Однако в русских пословицах и по- 
Лай Янь-изюнь. Концепт «женщина» в русской фразеологии в сопоставлении с китайской

говорках «слишком мужественные» и даже мужеподобные по характеру женщины нередко становятся объектом иронии. «Чаще всего в русских и китайских пословицах встречаются зоонимы как номинативные единицы, образно характеризующие внутренние качества, состояния, поведения и действия человека» $[9$, с. 79]. И действительно, конь часто используется во фразеологии для описания сильной женщины: не баба, а конь; конь-баба.

В традиционных китайской и тайваньской культурах мужество и мужественность также не являются положительными качествами женщины, потому что женщина должна быть нежной, женственной. Как говорится: 荏荏查某 , 較贏勇 勇查某 (досл. «(Физически) слабая женщины лучще крепкой, здоровой женщи$H b l »)$.

Аксиологические особенности женщин, отраженные в ФЕ. Внутренние качества представляют собой важную составляющую человека. Как говорится, «красивая женщина без внутренних чар - это пирог ни с чем». Актуальность личных качеств человека отражается в том, что они описываются не только в русских, китайских и тайваньских фразеологизмах, но и во многих других мировых фразеологизмах. Ввиду того, что личным качествам женщины, обнаруживаемым в русских и южноминьских поговорках и пословицах, присущи различные по своему характеру черты, материалы в данной части разделены на две группы: позитивные и негативные качества.

Позитивные качества женщины. Как отмечалось выше, когда речь идет о важности ума и красивой внешности, последнее отступает на второй план, так как красота завянет, а ум не обманет, красота - до венца, а ум - до конца. Мудрость и добродетель принимаются как лучшие качества жены, а поскольку считалось, что семья - это основное место для женщины, эти два качества вполне логично можно воспринимать как качества идеальной женщины: 娶著好 某, 卡好做祖 (досл. 《Жениться на хорошей женщине лучше, чем быть дедушкой»). Под «дедушкой» в данном примере имеется в виду 'очень удачливый человек', потому что долголетие и богатое потомство считаются символом счастья.

Помимо мудрости и ума для прекрасной женщины также характерно послушание. Схожая особенность обеих культур заключалась в том, что в традиционном китайском обществе, как и в «домостроевском» русском, господствовал патриархат, поэтому девушка до брака должна была слушаться отца, а в браке мужа: 在家由父, 出嫁從夫 (досл. «Дома подчиняться отиу, в браке подчиняться мужу»). В русских ФЕ также обнаруживается подобное требование к женщине в семье: та должна быть «тише воды, ниже травы». Тем более женщина должна была прислуживать и родителям мужа: 好女事家官 (досл. «Хорошая женщина прислуживает родителям мужа»).

Позитивный образ женщины часто создается в контексте семейной жизни, например, как верная жена и заботливая мать. Как говорится: «Кошка да баба в избе, мужик да собака на дворе». В данной пословице женщина сравнивается с кошкой, а мужчина - с собакой; подчеркивается то, что главное место и сфера деятельности для женщины - дом и быт. Кроме того, кошка считается хранительницей домашнего очага, так как в древности русские считали, что острые ногти кошки изгоняют злых духов и кошка - друг домового. Аналогичное поня- 
тие обнаруживается и в южноминьском диалекте 《男人趁, 女人理》 (досл. «Мужчина зарабатывает, женщина ведет хозяйство»). Добродетельная жена не только умеет хорошо заботиться о доме, но и делать мужа лучше, так как она оказывает ему духовную поддержку: «С доброй женой горе - полгоря, а радость вдвойне»; 《某若會食氣, 厷 (翁) 就會長志》 (досл. 《Если жена умеет стойко переносить трудности, то дух/воля мужа укрепляется»). Жена также является советчицей мужа. Недаром говорится: «Худое дело, коли жена не велела».

Женщина может играть разные роли в семейной жизни, а как только она станет матерью, она должна быть «всемогущей». Подробное описание образа матери уже описывалось выше, здесь же мы ограничимся высказыванием М. А. Алексеенко, который отмечает: «Подавляющая позитивная аксиологичность и эмотивность языковых средств, выражающих концепт 'мать', значительно отличается от прагматики оязыковленного концепта 'женщина', который реализуется в языке многочисленными лексическими, фразеологическими и паремийными единицами преимущественно негативного характера, что имеет свои исторические, культурные, социальные и другие причины» [3, с. 422].

Негативные качества женщины. Как говорилось ранее, прагматика концепта 'женщина' в русских ФЕ обладает в основном негативными характеристиками. В частности, нами было отмечено, что ум далеко не постоянное качество женщины. Раньше говорили, что «женская логика - отсутствие всякой логики» и даже шутили над умом женщины, сопоставляя длину ее волос с умственным уровнем: «y бабы волос длинный, а ум короткий». Традиционно в китайской культуре считалось, что женщине лучше быть бесталанной. Данная идея проявляется в южноминьском фразеологизме: 查 某图仔無才, 便是德 (досл. «Добродетель женщиныь в отсутствии таланта»). Способность как положительное качество человека в общем не оценивалась как позитивное качество женщины. О властной и сильной женщине говорят, что 《雞母啼, 破人家》 (досл. «Курииа закричит семья разрушится»). Это означает: природа устроена так, что утром должен кричать петух, а если бы кричала курица, то считается, что мир будет уничтожен. Речь в данном примере идет о том, что если женщина имеет власть, делает работу мужчины, то последствия будут разрушительные. В русских ФЕ обнаруживается то, что такую женщину также не одобряют: «Ей не юбку, а штаны носить».

Болтливость - известный стереотип отношения к женщине: «волос долог, a язык длинней; Где баба, там рынок; где две, там базар; Две бабы - базар, три бабы - ярмарка»; ср. кит.: 三個查某人菜市場 (досл. «Три женщины - рынок»). Рынок и базар часто ассоциируются с болтливой женщиной, поэтому в разговорной речи широко распространен фразеологизм базарная баба. Согласно народной мудрости, женщина, у которой широкий рот, обычно болтливая [17, с. 19]. Иронизируя над женщиной, речь которой характеризуется неразумностью, часто говорят: 一隻喙若雞母尻川 (досл. «Клюв как попа курищьl»). Слова женщины нельзя воспринимать всерьез, так как «кто бабе поверит, трех дней не проживет».

Считается, что сердце женщины непредсказуемо, поэтому характеризуя период теплой погоды в начале осени, русские используют притяжательное прилагательное, образованное от слова баба, и называют этот период бабьим летом 
Лай Янь-изюнь. Концепт «женщина» в русской фразеологии в сопоставлении с китайской

(напоминаем, что в южноминьских ФЕ переменчивый характер мачехи сравнивают с нестабильной весенней погодой).

Как отмечает Чжэн, у женщины тонкая душа, поэтому она порой бывает сентиментальна $[18$, с. 160$]$. Возможно, именно поэтому считается, что ревность характерна именно для женщины: 十婦九妒 (досл. «Девять из десяти женщин ревнивы»). А «в русских пословицах ревность приписывается скорее мужу, чем жене, при этом прослеживается неодобрительное отношение к ревнивцу, ревнивый муж опасен» $[4$, с. 40].

В русском языке широко распространены две перифрастические номинации, обозначающие женщину, но имеющие противоположный по прагматическому значению смысл: 'слабый пол' и 'прекрасный пол', где первая ФЕ отличается от второй своей негативной оценочностью. В качестве примера цитируем строку из поэмы Н. А. Некрасова «Кому на Руси хорошо»: «Горох - что девка красная, кто ни пройдет, щииннет». Слеза как символ слабости вызывает ассоциации с женским полом. Во фразеологии обоих языков (русского и южноминьского диалекта китайского) находим примеры о слезливой женщине: «Без плачу у бабы дело не спорится»; 多油厚㳯, 多查某厚眼屎 (досл. «В плохом масле много осажденных примесей, у плохой женщины много слез»).

Негативный образ женщины часто формируется и через ее сопоставление с мужчиной - «прагматическим антонимом» женщины. Следует подчеркнуть, что ФЕ такого рода оформлены не только на стереотипных представлениях о психологических качествах мужчины и женщины, но и на основе их биологических различий. Здесь мы остановимся лишь на примерах, иллюстрирующих противопоставление психологических особенностей обоих полов: «дорого стоит мужская слеза; в чем деду стыд, в том бабе смех». Еще раз отметим, что действительность в определенной степени отражается в языке, а в патриархальных обществах «мужчины, как доминирующая группа, создали язык, мышление и действительность» $[12$, c. 117]. Следовательно, в ФЕ южноминьского диалекта и русского языка обнаруживается картина, в которой женщина считается человеком второго сорта, который не может сравниться с представителем мужского пола и который подчиняется мужчине (ср. пословицу: «от намего ребра нам не ждать добра»).

По мнению В. С. Третьяковой, «культура, в том числе речевая, основывается на национальном менталитете, под которым понимается образ и способ мышления языкового коллектива, мироощущение и мировосприятие народа, отраженные в языке» $[15$, с. 117$]$. В историческом прошлом женщину ставили в неблагоприятное положение в русском, китайском и тайваньском обществе (здесь речь идет об обществе ханьцев, т. е. переселенцев из материкового Китая, в отличие от некоторых племен аборигенов, часть из которых матриархальная), что и сказалось во фразеологии как важном элементе языка, отражающем особенности культуры народа, нации, этноса. Изучая фразеологию русского языка и южноминьского диалекта, посвященную образу женщины, можно обнаружить противоречивое отношение к женщине, сложившееся в обеих культурах. С одной стороны, используя ФЕ, люди шутят над тем, что женщина неполноценна по сравнению с мужчиной, а с другой - одобряется идея того, что женщина должна подчиняться мужчине и что ей не надо быть такой сильной, способной и властной, как мужчина. В целом подтверждается сделанный В. Н. Телия вывод о том, что среди 
наиболее характерных для русского менталитета взглядов на женщину, можно отметить следующие: 'базарная баба', 'сосуд скудельный', 'куриные мозги' и другие [13, с. 261-268].

Несмотря на то, что образ женщины часто носит негативный характер, в проанализированных материалах мы находим описание и положительных качеств женщины. Важно указать, что это во многом связано с социальными ролями, которые играет женщина. Женщина позитивно описывается в ФЕ, когда она ведет хозяйство, воспитывает детей и заботится о семье.

Рассмотрев русскую и южноминьскую фразеологию, связанную с номинацией и различными характеристиками женщины, мы пришли к следующему выводу: аспекты социального образа, физических характеристик и психологических особенностей женщины, отраженных в ФЕ данных двух языков, тесно связаны друг с другом, что наглядно иллюстрируют такие ФЕ, как, например, комбинация физическое качество + социальная характеристика: «жена красавица - слепому радости» или физическое качество + психологическая характеристика: «у бабы волос длинный, а ум короткий», или социальная + психологическая характеристика: «с доброй женой горе - полгоря, а радость вдвойне». Нельзя считать, что имидж женщины в ФЕ этих языков всегда негативный. И в этом плане социальный образ женщины (к примеру, ее семейный статус и роль в семье) оказывает значительное влияние, так как, во-первых, позитивными психологическими характеристиками в большинстве случаев обладают женщина-мать и женщинажена, во-вторых, положительные (с точки зрения общества) физические особенности идут на пользу женщине в браке, а такие физические характеристики, как «высокий» возраст, высокий рост и мужеподобность, которые мужчины не оценивают и в их глазах считаются отрицательными, мешают женщине выйти замуж и, соответственно, получить роль жены и/или матери, что потенциально может улучшить ее образ. Таким образом, концепт 'женщина', отраженный в русской и тайваньской фразеологии, имеет тесную связь с традиционными культурноисторическими ценностями обоих народов в плане семьи (многие из которых сегодня уже стали стереотипными).

Рассмотренные ФЕ, как правило, отражают ретроспективный, диахронический взгляд фразеологии на женщин. Особенности «фразеологической синхронии» в употреблении фразеологизмов, по-разному характеризующих женщину, как нам представляется, должны стать объектом отдельного научного исследования.

\section{Литература}

1. Алексеенко М. Женские стереотипы в русской народной речи // Wyraz i zdanie w językach słowiańskich 6. Opis, konfrontacja, przekład. Pod redakcją Michała Sarnowskiego i Włodzimierza Wysoczańskiego. Wrocław, 2008. C. 13-23. Текст: непосредственный.

2. Алексеенко М. А. Концепт «женщина» в русской диалектной речи // Varietcten im Slavischen. Ausgewählte Beiträge. Heidelberg Publikationen zur Slavistik. Linguistische Reihe. Alexander Bierich, Peter Lang (Hrsg.) / Frankfurkt am Main, 2009. Band 17. C. 59-75. Текст: непосредственный.

3. Алексеенко М. А. Концепт «мать» в синхронной динамике языковой картины миpa // Грани слова: сборник научных статей к 65 -летию В. М. Мокиенко. Москва: ЭЛПИС, 2005. С. 415-422. Текст: непосредственный.

4. Алиева Ш. А., Омарова П. М. Репрезентация ревности в английских и русских пословицах // The theory and practice of gender studies in world science: materials of the VII 
Лай Янь-изюнь. Концепт «женщина» в русской фразеологии в сопоставлении с китайской

international scientific conference on May 5-6, 2016. Prague: Vědecko vydavatelské centrum Sociosfera-CZ, 2016. С. 38-41. Текст: непосредственный.

5. Багаутдинова Г. А. Человек во фразеологии: антропоцентрический и аксиологический аспекты: автореферат диссертации на соискание ученой степени доктора филологических наук. Казань, 2007. 45 с. Текст: непосредственный.

6. Вальтер Х., Малински Т., Мокиенко В., Степанова Л. Русская фразеология для немцев. Санкт-Петербург: Златоуст, 2005. 232 с. Текст: непосредственный.

7. Домострой. Юности честное зерцало. Русские пословицы и поговорки о семье. URL: http://www.wco.ru/biblio/books/domostroy/main.htm (дата обращения: 26.11.2017). Текст: электронный.

8. Зимин В. И. Словарь тезаурус русских пословиц, поговорок и метких выражений. Москва: Аст-пресс, 2012. 736 с. Текст: непосредственный.

9. Коробейникова А. А., Хуан Ю., Давыдова Е. А. Образные номинации человека в русских и китайских пословицах // Вестник Оренбургского государственного университета. 2015. № 11 (186). С. 77-82. Текст: непосредственный.

10. Краткий словарь когнитивных терминов / Е. С. Кубрякова, В. З. Демьянков, Ю. Г. Панкрац, Л. Г. Лузина; под общей редакцией Е. С. Кубряковой. Москва: Изд-во МГУ, 1996. 400 с. Текст: непосредственный.

11. Семенова Д. В. Гендерный аспект концептуального анализа лексем «мужчина» и «женщина» (на материале фразеологии английского, русского и кабардинского языков): автореферат диссертации на соискание ученой степени кандидата филологических наук. Нальчик, 2006. 25 с. Текст: непосредственный.

12. Спендер Д. Мужчина создал язык // Введение в гендерные исследования. Ч. ІІ. Хрестоматия / под ред. С. В. Жеребкина. Харьков: ХЦГИ, 2001; Санкт-Петербург: Алетейя, 2001. С. 775-783. Текст: непосредственный.

13. Телия В. Н. Русская фразеология. Семантический, прагматический и лингвокультурологический аспекты. Москва: Школа «Языки русской культуры», 1996. 288 с. Текст: непосредственный.

14. Тер-Минасова С. Г. Язык и межкультурная коммуникация. Москва, 2000. 146 с. Текст: непосредственный.

15. Третьякова В. С. Речевой конфликт и аспекты его изучения // Юрислингвистика. 2004. № 5. С. 112-120. Текст: непосредственный.

16. Эмирова А. Оппозиция «мужчина - женщина» в русской фразеологии // Грани слова: сборник научных статей к 65-летию В. М. Мокиенко. Москва: ЭЛПИС, 2005. С. 165-169. Текст: непосредственный.

17. Цзян: 江寶釷。台灣閩南語謠彥中反映的性別意識。台灣文學學報, 2016, 28, 132. Текст: непосредственный.

18. Чжэн: 鄭怡卿。臺灣閩客譫語中的女性研究。國立中央大學中國文學系 碩士論 文。2008, 237 頁. Текст: непосредственный.

Статья поступила в редакцию 24.11.2020; одобрена после рецензирования 28.01.2021; принята к публикации 25.03.2021. 


\title{
CONCEPT «WOMAN»IN RUSSIAN PHRASEOLOGY \\ (IN COMPARISON WITH SOUTHERN MIN DIALECT)
}

\author{
Yen-Chun Lai \\ Research Assistant, \\ National Chengchi University \\ No 64, Sec. 2, Chinan Rd., 116, Taipei, Taiwan \\ lisalai0106@gmail.com
}

Abstract. This article reviews the concept 'woman' in Russian phraseology in comparison with the Southern Min dialect. The author reveals physical, psychological and social characteristic of women reflected in phraseology. Proverbs, common sayings and phraseologisms (idioms) are important elements in the linguoculture of a particular people. Phraseological units are created on the base of a figurative representation of society about certain subject in reality, and thus they reflect its history, culture and worldview. Foreigners may encounter difficulties in understanding and getting a good knowledge of phraseology, since their linguistic view of the world may differ from native speaker or people representing a given culture. The study helps identify typical ideas about woman in traditional Russian and Taiwanese societies.

Keywords: phraseology; woman in phraseology; stereotypes about women; humanitarian values.

\section{For citation}

Yen-Chun Lai. Concept «Woman» in Russian Phraseology (in comparison with Southern Min Dialect). Bulletin of Buryat State University. Philology. 2021; 1: 20-32 (In Russ.).

The article was submitted 24.11.2020; approved after reviewing 28.01.2021; accepted for publication 25.03.2021. 